\title{
Explanatory dispositionalism
}

\section{What anti-Humeans should say}

\section{Barbara Vetter ${ }^{1}$}

Received: 28 October 2019 / Accepted: 11 September 2020 / Published online: 23 September 2020 (c) The Author(s) 2020

\begin{abstract}
Inspired both by our ordinary understanding of the world and by reflection on science, anti-Humeanism is a growing trend in metaphysics. Anti-Humeans reject the Lewisian doctrine of Humean supervenience that the world is "just one little thing and then another", and argue instead that dispositions, powers, or capacities provide connection and (some say) activity in nature. But how exactly are we to understand the shared commitment of this anti-Humean movement? I argue that this kind of anti-Humeanism, at its most general level, is to be understood neither as a view about ontology (the existence of certain properties) nor about fundamentality, but rather as a specific claim about what explains what.
\end{abstract}

Keywords Anti-Humeanism · Dispositions · Dispositionalism · Ontology · Metaphysics

\section{Introduction}

What is metaphysics all about? According to the Quinean tradition (most prominently, Quine 1948), metaphysics is basically ontology, a matter of answering the question 'what there is' (and, in the second instance, how things are; see Janssen-Lauret (2017, p. 6). Ontological theories earn their keep by providing explanations; their assessment is a matter of weighing the ontological costs against the explanatory benefits. According to an older tradition that has recently had a revival (e.g., Schaffer 2009), metaphysics is not primarily about what there is but about 'what grounds what': the explanatory orders and hierarchies among what there is. On this approach, explanation is not relegated to the task of evaluating theories; it belongs in the content of metaphys-

Barbara Vetter

barbara.vetter@fu-berlin.de

1 Institut für Philosophie, Freie Universität Berlin, Habelschwerdter Allee 30, 14195 Berlin, Germany 
ical theories. ${ }^{1}$ The explanatory conception, in turn, allows for two readings. A liberal reading takes metaphysics to be about explanatory relations at all levels of reality; a more restrictive reading takes it to be properly concerned only with that which explains everything else: the ultimate explanantia, the fundamental. This latter reading is then neatly combined with a similarly restrictive reading of the Quinean answer, where metaphysics is about what there is fundamentally - those existents which explain all others.

One aim of this paper is to apply this second-order debate on the aims of metaphysics to a central first-order metaphysical debate, the debate between Humeans and antiHumeans.

Humeanism finds its canonical (if incomplete) formulation in David Lewis's thesis of Humean supervenience: the view that 'all there is to the world is a vast mosaic of local matters of particular fact, just one little thing and then another ... we have an arrangement of qualities. And that is all. ... All else supervenes on that' (Lewis 1986b, p. ix f). Humean supervenience, in this formulation, is first and foremost a view on ontology, on what there is: an arrangement of qualities with no essential connection to each other. It is also a claim about fundamentality: it is the claim that the world is fundamentally 'an arrangement of qualities'. And since what there is, in the intended sense, is that which explains everything else (in Lewisian terms: on which all else supervenes), Humean supervenience is also the thesis that everything can be explained in terms of the Humean mosaic. ${ }^{2}$

Anti-Humeans reject this view of the world. To many of them it seems, as Judith Jarvis Thomson has said about the closely related thesis of perdurantism, 'a crazy metaphysic_obviously false' (Thomson 1983, p. 210); a metaphysics better suited to describe the happenings on a computer screen, where the image is constituted by 'just one pixel and then another', than the rich and connected world we live in. The world of Humean metaphysics is, at bottom, devoid of laws which connect and govern the different happenings in the world, leaving it a mystery why things behave in lawful ways (Bird 2007); it is indeed devoid of any kind of genuine modality, which as a consequence is 'outsourced' to other possible worlds that are equally barren (Vetter 2011); and it is devoid of real causation, of dispositions, and powers, all of which must be tenuously reconstructed, losing much of their 'oomph' in the process. Such a view of the world, according to anti-Humeans, does justice neither to the manifest image of the world, which is replete with tendencies and powers, causes and possibilities, nor to the scientific image. Science, the anti-Humeans have pointed out, is difficult to understand without the appeal to powers and dispositions, both in terms of its results (see Bird 2007; Ellis 2001; Harre 1970, and many more) and in terms of its practice (Blackburn 1990; Harre 1970, p. 90; Shoemaker 1980). From particle physics through chemistry

\footnotetext{
${ }^{1}$ I am using the terms 'explain' and 'explanation' in an objective sense throughout. The most prominent contemporary gloss on such objective explanation is grounding, and I will occasionally switch between the two idioms. But what I say in this paper should be independent of our precise conception of explanation and any particular conception of grounding.

${ }^{2}$ Lewis does not speak of explanation, but instead of (asymmetric) supervenience ('of the large upon the small and many', see his Lewis 1994), coupled with conceptual analysis. More recent discussions of Humeanism have availed themselves of more substantial explanatory vocabulary, understanding Humeanism as the view that everything holds 'in virtue of' the Humean mosaic (Loewer 1996, p. 102) or that 'facts about the laws are grounded in [the Humean, qualitative] base' (Bhogal 2017, p. 458).
} 
and biology all the way to the social sciences, the world that science describes to us seems to be one of powers and dispositions; or so the anti-Humean maintains. Some have argued even that science forces on us a picture of nature as 'active', much as we take ourselves to be in the manifest image (Ellis 2001; Groff 2013; Harre 1970; but see Bird 2007, pp. 126-128 for criticism). Brian Ellis gives a minimal gloss on the activity at issue on which anti-Humeans might agree: while for the Humean, laws are 'imposed on things whose identities are independent of the law', the anti-Humean claims that 'the laws are immanent in the world, not superimposed on it' (Ellis 2001, p. 1$)^{3}$

Anti-Humeans are united primarily by their rejection of the Humean picture, and we might take 'anti-Humeanism' simply to refer to the negation of the Humean doctrine. In this broad sense of 'anti-Humeanism', it would include such views as those of Lange (2009), who takes there to be primitive subjunctive facts in the world, or Maudlin (2007), who takes laws to be primitive. But very often, the label 'anti-Humeanism' is taken to refer to a more specific positive view, one which takes Aristotle rather than Hume as its philosophical hero and is characterized by appeal to properties that are variously called powers, potencies, potentialities, or dispositions. It is anti-Humeanism in this narrow sense, sometimes also called dispositionalism, that will be my concern in this paper. In what follows, and unless stated otherwise, I will use 'anti-Humeanism' and its cognates in this narrow sense.

There is no canonical statement of anti-Humeanism, in this narrow sense, like there is for neo-Humeanism. It would be useful to have a general characterization of what anti-Humeanism amounts to, however, in order to see more clearly what is at stake in the debate between Humeans and anti-Humeans, and to lay the ground for disagreements within the anti-Humean camp about matters of detail. Such a general characterization, besides making some sort of appeal to dispositions or powers, would have to meet two requirements. First, it would have to capture a genuine disagreement with the Humean. This seems too obvious to merit stating, but we will see below that it is harder to achieve than one might have thought. Let us refer to this requirement as Disagreement. Moreover, if we aim (as I do) to formulate anti-Humeanism in general, rather than one specific version of it, then we must do more than disagree with the Humean. We must formulate that disagreement in such a way that we get to the heart of the disagreement; we must isolate exactly what is at stake in it. To achieve this, we must take care to characterize anti-Humeanism in terms that (i) do not rule out views which should count as anti-Humean, e.g. by saddling the anti-Humean with additional metaphysical commitments extraneous to her anti-Humeanism; and that (ii) make some sense of the core motivations for anti-Humeanism, as they arise from both the

\footnotetext{
3 The idea that understanding activity requires causal powers is widespread. Thus in the introduction to a volume of his collected papers, Harry Frankfurt writes: 'In the seventeenth century, mechanism became established as the dominant worldview of our culture ... In the eighteenth century, the notion of an efficient cause was itself eviscerated by a devastating critique of the idea of inherent power. These compelling philosophical developments have made it difficult to give a good account of the difference between being active and being passive. For if things are understood as having neither purposes nor powers, in what sense is it possible to comprehend them as being active at all?' (Frankfurt 1998, p. viii) Frankfurt goes on to understand activity in terms that do not require 'inherent power' but appeal instead to the structure of the will.
} 
manifest and the scientific image. Let us call this requirement—encompassing both (i) and (ii) - the requirement of Generality.

While there is not much explicit debate on how to characterize anti-Humeanism in general, the view is typically characterized in ontological terms: as the view that there are properties of a certain description, to wit, dispositions or powers; or, differently put, a view about what the properties that there are, are like (see, e.g., Molnar 2003, p. 159; Bird 2007, p. 45; Williams 2019, p. 10f.; and many others ${ }^{4}$ ). Sometimes it is characterized as a view about what's fundamental, though that is typically coupled with ontology: it is a claim about what the fundamental properties are (see Bird 2007; Williams 2019 for explicit statements). I believe that neither of these two characterizations is adequate. In Sect. 2, I will argue that appeal to fundamentality, whether or not it is coupled with appeal to ontology, is unsuited as a general characterization of anti-Humeanism because it fails to satisfy Generality. It may yet work as the characterization of a specific version of anti-Humeanism, but it cannot be used to formulate its core and common commitment. In Sect. 3, I go on to argue that appeal to ontology, however it is construed, must fail to satisfy at least one of our requirements. In fact, one popular version of an ontological characterization of anti-Humeanism will turn out to fail our requirement of Disagreement: it is not suited to count even as a particular version of anti-Humeanism, since Humeans can agree with it.

I will then suggest, in Sects.4-6, that for the purposes of formulating antiHumeanism we take up a third, underexplored conception of metaphysics: the idea that metaphysics is about 'what grounds what', at all levels, not just the fundamental. I take anti-Humeanism to disagree with Humeanism about what explains what quite generally. Sections 4-6 motivate, introduce, and spell out a characterization of antiHumeanism guided by the idea that dispositions are not the problematic explanandum which Humeans take them to be, but should rather serve as a central explanans in our metaphysical theories. I will formulate a minimal version of this view, which I take to encapsulate the shared core commitment of anti-Humean metaphysics, and indicate ways in which it can be strengthened to yield different versions of the view.

\section{Fundamental dispositionalism}

Fundamental dispositionalism is the view that the world is fundamentally dispositional. Typically, this view is formulated in combination with two background assumptions: first, realism about properties (be they universals, as in Bird 2007, or tropes, as in Molnar 2003); and second, a restrictive view on what there is (agreeing with Lewis 1983 that what is at stake are the sparse properties only). In this combination, it can be formulated simply as the view that there are dispositional properties, since the quantifier is understood to range over only the sparse, fundamental properties. But fundamental dispositionalism can be understood without either of these commitments.

Within a more liberal ontology of properties that allows for both sparse and abundant properties, it will say that there are fundamental dispositional properties, while

\footnotetext{
4 Section 2 of Azzano (2019) provides an illuminating list of quotations.
} 
remaining silent on the non-fundamental properties (Bird 2016 can be read as an argument for such a view). Without the commitment to property existence, the view will say that whatever there is fundamentally (be it properties, objects, or something stranger than either) is dispositional. On this understanding, fundamental dispositionalism is compatible with nominalism; it might, for instance, adopt a kind of causal nominalism (see Whittle 2009) for the fundamental level, or appeal to the notion of generic essence, as recently suggested by Vogt (ms).

In this section, I want to argue against fundamental dispositionalism in any variety. For simplicity, and because it is the most common version of the view, I will formulate the view in its combination with property realism (as defended, e.g., in Bird 2007; Williams 2019), but the argument will not depend on that assumption; what it targets is simply the focus on the fundamental. Even so, my argument will not attack the truth of fundamental dispositionalism: for all I say here, fundamental dispositionalism might be true. Nor will I attack its claim of being opposed to Humeanism: for all I say here (and, I believe, in actual fact), it is indeed incompatible with Humeanism. What I will argue is merely that fundamental dispositionalism violates my requirement of Generality as set out in Sect. 1 .

It is clear, given the initial motivation set out in Sect. 1, that the interest of antiHumean theories lies not only in an account of the fundamental level. As Bird (2016) has pointed out (in arguing that there is no direct path from fundamental dispositionalism to a more liberal dispositionalist ontology), the mere fact that there are fundamental dispositions tells us nothing about the dispositions of middle-sized objects, let alone of agents like ourselves. Given fundamental powers, we could derive the fundamental laws from them and then provide explanations of everything else along Humean lines. Nothing is said about chemistry, biology, or the social world, much less about our ordinary understanding of the world, the 'manifest image'. Fundamental particleswhichever they are-may be considered 'active' in Ellis's minimal sense of having within them the source of the laws that govern them; but nothing is said about those things whose activity we actually care about. While defenders of fundamental dispositionalism appeal to those very same considerations to urge caution in going beyond the fundamental (or indeed in appeal to such vague terms as 'activity'), other anti-Humeans will take them as strong motivations to develop a different theory. An anti-Humean theory that is entirely silent on such properties as a wire's power to conduct electricity, an eagle's capacity to spot its prey, and our own agential abilities will, even if it is true, remain deeply disappointing.

Disappointment, of course, is no argument, but in this case it should motivate us to look further. The fundamental dispositionalist might respond that fundamental dispositionalism was presented as the minimal shared commitment of all anti-Humeans; those moved by the initial motivation are at liberty to add further commitments and claims to it in their theories. However, fundamental dispositionalism will not do even as a minimal shared commitment of anti-Humeans, because it violates Generality in another way. This is our second and more decisive problem.

The second problem for fundamental dispositionalism is that it ties anti-Humeanism to a particular metaphysical assumption that should be independent of the Humeanism/ anti-Humeanism debate. This assumption, which has not been discussed so far as I can see, is the assumption that there is a fundamental level. That is, admittedly, an 
assumption which is widely shared among contemporary metaphysicians, although it was hotly debated in the early modern period (and is critically discussed in the current literature as well: see Bliss 2019; McKenzie 2011; Schaffer 2003), and has certainly not been settled empirically. Now suppose that we were, for whatever reason, convinced that there is no such thing as a fundamental level, or at least that we should be agnostic on the question. Would (and should) that end the debate between Humeans and antiHumeans? I think not. Humeans think that our world contains no irreducibly modal or causal features, that it is just 'a vast mosaic of local matters of particular fact' — an idea that could still be upheld were the mosaic not constructed out of elementary categorical building blocks, but (to remain in the picture) out of categorical building blocks which were in turn constructed out of further categorical building blocks, and so on to infinity. The anti-Humean thinks that our world comes with modal and/or causal features built into properties (or alternatively into how things are), and not bestowed onto them from the outside. That idea, too, could be upheld without a fundamental level, roughly by saying that as we go down from the less to the more fundamental (without ever reaching rock-bottom), we will always find properties with their modal/causal character built into them. The problem for present purposes is that such a view would no longer count as fundamental dispositionalism - if there is no fundamental level, then the claim that the fundamental level is dispositional is either false or meaningless.

Thus fundamental dispositionalism not only fails to do justice to a central antiHumean motivation; in order to make sense of its core claim, it is also committed to a metaphysical thesis that should not be at stake in the debate between Humeans and anti-Humeans. Thus fundamental dispositionalism fails to satisfy our requirement of Generality twice over. This, to repeat, is not a point against the truth of fundamental dispositionalism. To an anti-Humean who is in any case committed to there being a fundamental level, and who is already less moved by the motivations I have cited, it may be the best choice. But it is an unsuitable candidate as a general formulation of what anti-Humeanism amounts to.

\section{Ontological dispositionalism}

Ontological dispositionalism is the claim that some or all genuine properties are dispositional, or are powers — some, according to the moderate ontological dispositionalist; all, according to the pandispositionalist.

One objection we might have against ontological dispositionalism is that it fails to satisfy Generality: it incurs a commitment to the existence of properties, thereby excluding the option of a nominalist anti-Humeanism, as it is suggested in Whittle (2009) and Vogt (ms). ${ }^{5}$ Since that is a minority view, however, I want to point out a different and more pervasive problem of ontological dispositionalism, which arises from the appeal to 'genuine' properties.

Both the moderate and the pandispositionalist version of ontological dispositionalism quantify over 'genuine properties' (though not always with this exact expression),

\footnotetext{
5 Tugby (2013) argues that dispositionalists ought to be Platonists. Even if he is right, this seems a prime example of a dispute within the anti-Humean camp, and not a reason to exclude nominalist versions of anti-Humeanism by definition.
} 
staking out a claim that applies to either some or all of them. But what are 'genuine properties'? The attribute 'genuine' is in need of interpretation, but it is clearly needed. If the ontological dispositionalist's claim was about properties in any sense, including what (Lewis 1986a) calls 'abundant' (where to every predicate corresponds a property), then moderate ontological dispositionalism would be trivial—even the hardcore Humean agrees that some, indeed many, abundant properties are dispositional. Pandispositionalism, meanwhile, would be faced with counterexamples that are probably insurmountable — negative properties, such as being non-blue, disjunctive properties, such as being round-or-yellow, mere Cambridge properties, such as being $10 \mathrm{~m}$ from a burning barn, and such properties as being identical to Socrates. Thus both moderate dispositionalists and pandispositionalists need to draw a sharp line between the properties that they are concerned with, on the one hand, and the merely abundant properties, on the other. Some deny that abundant properties deserve the name 'property' in the first place, claiming that what we have in these cases are merely predicates (Molnar 2003, pp. 25-28; Heil 2003, ch. 3); others accept that abundant properties mark one legitimate use of 'property' but insist that they are using the word differently (Bird 2018). For present purposes, it does not matter which of these views is adopted, though I will sometimes for ease of expression speak as if the ontological dispositionalist holds the second view.

Since ontological dispositionalism is an ontological claim, the distinction between genuine and merely abundant properties (or properties and mere predicates) had better be a substantial ontological one itself. How exactly are the genuine properties to be delineated?

One option for the ontological dispositionalist is to go fundamental (as do Bird 2007 and Williams 2019): the genuine properties, those about which she is making a claim, are the fundamental properties. That is, of course, simply a version of fundamental dispositionalism, and as such it fails to satisfy our requirement of Generality, for the reasons given in Sect. 2. So let us put this view-which we might call 'fundamental ontological dispositionalism' - aside and look at the alternatives.

The second option for the ontological dispositionalist is what I would like to call liberal ontological dispositionalism. Liberal ontological dispositionalism does not restrict the 'genuine properties', some or all of which it claims to be dispositional, to the elite class of fundamental properties. Nor, of course, does it include the entire plebs of so-called abundant properties among its reach. Instead, liberal ontological dispositionalism strives to find a middle ground of properties that are real but not necessarily entirely fundamental. Witness (Anjum and Mumford 2018, 8f.): 'saying that our account is not restricted to the sparse properties of fundamental physics does not mean that anything goes. We do not allow disjunctive or other gerrymandered properties, for instance. ... Nor do we allow negative properties ... Nor is it clear that we should include relational properties'.

Liberal ontological dispositionalism certainly has a better prospect of capturing the entirety of the anti-Humean's initial motivation, and it can easily afford to remain agnostic about whether or not there are fundamental properties. It is no surprise, then, that its defenders include illustrious dispositionalists such as Anjum and Mumford (2018), Ellis (2001), Molnar (2003), Mumford and Anjum (2011) and many more (even, cautiously, Bird 2018). 
What liberal ontological dispositionalism needs, however, is a clear way of capturing the distinction between the genuine and the merely abundant properties. This was an easy task for fundamental dispositionalism. But we are working with a more liberal conception now. How is a less restrictive dividing line to be drawn?

I know of two responses to this question. The first invokes what is often called the 'Eleatic Principle': 'everything that we postulate to exist should make some sort of contribution to the causal/nomic order of the world' (Armstrong 2004, p. 37, see also Heil 2003, p. 24). For the purposes of liberal ontological dispositionalism, of course, this principle can be used if (and only if) we assume that non-fundamental entities (and properties, in particular) do make such a contribution: a putative property is genuine, then, if it makes the right kind of contribution to the causal/nomic order of the world. (Heil 2003 uses the principle within the context of what looks more like fundamental dispositionalism). ${ }^{6}$ But how are we to adjudicate whether or not a putative (non-fundamental) property does make the right kind of contribution? Here the second response helps. The second response that is sometimes given to my question is that the genuine properties are the ones that are indispensable to science and (true) scientific theories and explanations (see, e.g., Bird 2018; Molnar 2003, p. 27; Schaffer 2004). For simplicity, I will use 'account' as a shorthand for both theories and explanations in what follows, and understand these to be the true, not our actual, scientific accounts. Thus one might say: if a (putative) property plays an indispensable role in scientific accounts, then it is genuine. I take this second response to be a clarification of the first, and will therefore focus on it in what follows. It corresponds nicely to what Schaffer (2004) calls the 'scientific conception' of sparse (i.e., genuine) properties. ${ }^{7}$

The response seems to nicely distinguish the genuine properties from the fundamental properties on the one hand, and from the merely abundant properties on the other. On the one hand, genuine properties go beyond fundamental properties (if there are any) just as science goes beyond fundamental physics (or whatever we take to be the science of the fundamental level); it includes chemistry, biology, sociology, and so forth. Many properties that play a role in those sciences, from water-solubility to the tendency to adopt a particular political view, seem clearly dispositional, have genuine explanatory roles to play, and are clearly not fundamental. On the other hand, the genuine properties are a more select group than the abundant properties, since not every

\footnotetext{
${ }^{6}$ Does the answer threaten circularity, by circumscribing the genuine properties in terms of causal/nomic notions, and then explaining causal/nomic phenomena in terms of the genuine-dispositional—properties? I do not think so. Appeal to causes and laws is not meant to be an analysis of what a genuine property is, but merely to help us pick out the right extension. This leaves wide open what the metaphysical relation is, say, between laws and properties. Thanks to an anonymous reviewer for raising this point.

7 What I have said does not, of course, exhaust the possible responses. Dorr and Hawthorne (2013) offer a range of roles that 'natural properties' (here referred to as 'genuine properties') are meant to play, and the ontological dispositionalist may pick other items from the list, such as reference magnetism or perfect similarity. I will not discuss these further here, for three reasons. (i) The answers I give in the text are the ones that are actually found in the dispositionalist literature. (ii) Dorr and Hawthorne's discussion, in accordance with their Lewisian precedents, describe roles only for either 'perfectly natural' properties, which are plausibly the fundamental properties, or for a comparative ordering among the natural properties, which is simply not what the ontological dispositionalist ought to be looking for. (iii) The best candidates among the criteria for natural properties to push us towards a non-fundamentalist conception is indeed explanatory and scientific power, as Schaffer (2004) has shown. Thanks to an anonymous reviewer for pressing me on this.
} 
hum-drum property plays a role in scientific accounts: disjunctive, negative, and mere Cambridge properties appear not to qualify, and that paradigm example of a merely abundant property, being grue, has certainly not played a role in any scientific account. Finally, the characterization is clearly neither ad hoc nor speculative; it provides liberal ontological dispositionalism with a solid tie to scientific practice.

However, the distinction between non-fundamental genuine properties on the one hand, and merely abundant properties on the other, is not stable. Here is why. ${ }^{8}$

Which properties figure indispensably in (true) scientific accounts is a highly contingent matter, and subject to change over time. Biological accounts deal with the life-forms that have actually evolved on earth (or potentially elsewhere); but which life-forms did evolve is a highly contingent matter that could have been settled very differently. As a consequence, which properties figure indispensably in biological explanations is a contingent matter that could have turned out differently, and may itself be subject to change over time. The properties of being a mammal, of being able to breathe oxygen or capable of photosynthesis, have turned out to be very important in true biological accounts, but they might very well not have done so if evolution had gone differently. The properties of being a democratic state, of being disposed to adopt a particular political view, or of being able to speak convincingly to a large crowd, are all important in various true accounts of politics, sociology, and history; but that, too, might very well not have happened if human societies had developed differently or not at all. In short: a property's being indispensable to scientific explanations is contingent and changeable.

Now, liberal ontological dispositionalism is intended to be a theory of property existence, not just of the explanatory roles that properties can play. But property existence, at least for the realist, is not usually considered to be contingent and changeable in the same way that playing a role in a scientific account is. Thus it is not that the property of being a mammal or the property of being able to breathe oxygen came into being when they first and contingently acquired an indispensable role in explaining certain biological facts. Rather, the picture must be that the properties were there all along; being a genuine property is what qualified them for an explanatory role. On this picture, it is clear that not every genuine property need be called upon to play such a role, even if it could have been. But just as many genuine properties could have failed to play an indispensable role in a scientific account, so there may be other properties which could have, but never did come to play such a role. These contingencies can hardly make a difference to the ontology of properties. Hence we should say that every property which could have played an indispensable role in scientific accounts is a genuine property.

But now we can see the conception of genuine properties beginning to explode.

For consider: which properties could have played an indispensable role in scientific explanation? The answer is, almost any property. Think about biology: a paradigm example of biological explanation is evolutionary explanation. If a property helped a life-form survive in its environment, then it is explanatory. (See Bird 2018 for details.) But environments could have developed very differently. It is easy to imagine environ-

\footnotetext{
8 The argument in the paragraphs that follow is a condensed version of my argument in Vetter (2018), where it is directed specifically against (Bird 2018); as is seen here, I think the argument generalizes to other versions of liberal ontological dispositionalism.
} 
ments that would have made an otherwise non-genuine-looking property indispensable for evolutionary explanation. As a toy example, imagine an environment $E$ where predators hunt by sight and can only see the colours red and blue. Imagine further that in $E$, we have species $\mathrm{A}, \mathrm{B}$, and $\mathrm{C}$, where specimens of $\mathrm{A}$ are yellow, speciments of $\mathrm{B}$ are green and brown, specimens of $\mathrm{C}$ are red. In such an environment, being neither-red-nor-blue is a property that is crucial for survival. It will also be indispensable for any good general explanation of why species A and B survived and thrived while species $C$ has been decimated or extinguished. The survival of species A and B is not best explained by their positive colour properties, the colours they actually have, but rather by their shared negative colour property: being neither red nor blue. But this is hardly the kind of candidate which liberal ontological dispositionalism (or anyone else) envisages for being a genuine property! Now the environment I have imagined does not seem impossible, albeit rather simplified — environments of a similar structure could very well have, and perhaps really have, developed.

Even that paradigm example of a non-genuine property, the property of being grue, could have played a role. Consider, again, a toy example. Imagine a population that is dominated by philosophers, all extremely keen on Nelson Goodman's new riddle of induction. In such a population, the fact that something is grue (with some time $t$ settled to give a precise definition) might very well become a relevant explanatory factor: perhaps people will start collecting, manufacturing, and exhibiting things that are grue; wealth will be measured by how many grue things you own, and so on. (There are, of course, two ways of getting grue object: get something green that has been observed before $t$, or something blue that has not been observed before $t$. Prior to $t$, the first strategy will be easier to implement.) The explanation for why those objects play such an important role will not be their being blue or their being green, but plausibly their being grue. Alternatively, assume that at a time $t$ the human perceptual apparatus is affected around the world (perhaps by some environmental toxin) in such a way that colour perception switches between green and blue; and that humans are deeply affected by their perception of green. If that perception is caused, after $t$, by (what we now take to be) blue objects, then again the relevant explanatory property for the effect of colour on humans would be not being green, but being grue. ${ }^{9}$ As Schaffer (2015, p. 644) puts it, once we allow for existence beyond the fundamental level, '[w]hat emerges is general pressure towards a permissive and abundant view of what there is, coupled with a restrictive and sparse view of what is fundamental'.

In sum, it is much harder to draw a substantial line between the genuine and the merely abundant than is usually assumed. This is not to say that there is no difference between a property such as being spherical or soluble, on the one hand, and being grue or neither-red-nor-blue on the other. But the difference is much easier to accommodate when we see it as one of degrees, where some properties are more natural than others. This way of thinking is not open to liberal ontological dispositionalism, though. Liberal ontological dispositionalism must locate a distinction between existence and non-existence-a non-gradual distinction if ever there was one. If there is no such

\footnotetext{
9 For the sake of the example, I assume that colours are primary qualities: identical to the surface properties that give rise to them.
} 
distinction to be located, then the genuine properties will, after all, coincide (or very nearly coincide) with the abundant properties.

How does this affect liberal ontological dispositionalism? That depends. If the liberal ontological dispositionalist is a pandispositionalist, she will now be making a very strong claim: that all properties, at all levels, are dispositional. That claim, whatever its truth value may be, fails to satisfy our requirement of Generality: it is certainly not something that all dispositionalists will agree on, and it saddles the dispositionalist with a metaphysical commitment (the existence of abundant properties) which should not be at stake in the debate. If, on the other hand, the liberal ontological dispositionalist adopts a moderate position according to which some genuine properties are dispositional, then she fails to satisfy Disagreement. The Humean has no beef whatsoever with the idea that there are powers or dispositions among the abundant (or indeed the nearly abundant) properties. If you count being blue or red and being grue among your genuine properties - she will say - then sure, there are powers among the genuine properties! Liberal ontological dispositionalism, thus construed, has failed to disagree with the Humean.

Let us recap: Ontological dispositionalism is either fundamental, or liberal. Fundamental ontological dispositionalism (whether pandispositionalist or moderate), as a species of fundamental dispositionalism, fails to satisfy Generality. Liberal ontological dispositionalism, in turn, faces its own dilemma, at least given the standard way of spelling out its core claim and the restriction to genuine properties: it must be either pandispositionalist or moderate. But if it is pandispositionalist, it again fails to satisfy Generality; if it is moderate, it fails to satisfy Disagreement.

One conclusion we could draw from this is that there is simply no coherent formulation of anti-Humeanism that satisfies both criteria. Moreover, it might be said, failing to satisfy Disagreement is a more serious problem: it rules out a view even as $a$ version of anti-Humeanism. Failing Generality, however, rules out only that a view is the general statement of anti-Humeanism. Perhaps no such general statement is to be had. I will argue, however, that there is another way: we can provide a general characterization of anti-Humeanism that satisfies both criteria and makes it clear what is at stake in the debate.

\section{Towards an explanatory account}

We have seen that neither appeal to fundamentality, nor to ontology, will provide us with a characterization of anti-Humeanism that is both plausibly anti-Humean and sufficiently general. But there was a common element in all the attempts we have considered, one which has not taken centre stage as yet: explanation. In fundamental dispositionalism, the idea was that dispositions are among the fundamentalia, i.e., roughly, that which explains everything else without being explained itself. The problem was that the focus merely on the bottom level of explanation was too restrictive; easing that restriction, we can look at what explains what more generally. In ontological dispositionalism, the idea was that 'what there is' includes dispositions, but to get a sufficiently substantive picture of 'what there is' we needed, again, to look at what has an explanatory role to play. The problem was that, unless ontological dispositionalism 
went fundamental, the explanatory roles did not provide the sharp cut-off that ontological dispositionalism needed between what there is, and what there isn't; anything could play an explanatory role. But if we focus not on existence but on explanation itself, that is not a problem.

These observations suggest that we take a closer look at explanation. Given its presence, albeit sometimes implicit, in the extant accounts, there is some hope that the appeal to explanation will satisfy Generality. There is also hope that it will secure Disagreement (with the Humean), for it seems fair to say that the dispute between Humean and anti-Humean metaphysics concerns the explanatory order of the world. For the Humean, dispositions are a problematic phenomenon, an explanandum to be explained with other resources - 'ideally to be explained away, or entitled by a shotgun wedding to take the name of some decently real categorical property', in Hugh Mellor's well-known analogy (Mellor 1974, p. 157). For the anti-Humean, on the contrary, dispositions are the central explanans. They are the source of certain modal, causal, and nomic facts in the world. Let us look at that contrast in a little more detail.

The Humean explanation of a given disposition relies on two different kinds of factors. First, there is a categorical, i.e., non-dispositional property, the 'causal basis' of the disposition; this accounts for the fact that a disposition is a (typically intrinsic) property of its bearer. Second, there is some further factor-e.g., a law of nature-that supplies the categorical property with a causal-modal role; this accounts, as it were, for the disposition's dispositionality. The first factor, the causal basis, takes slightly different forms in the fundamental and the non-fundamental case. When we are talking about the fundamental level, the property that counts as a disposition's causal basis will be a fundamental, simple quality (or a conjunction of such qualities): a perfectly natural property about whose identity no more can be said than that it is the quality it is. When talking about the non-fundamental level, the causal basis will typically be a more complex, structural property: the glass's being composed of such-and-such molecules in such-and-such bonding structure, for instance, the salt's being composed of certain positive and negative ions, the bird's having a particular arrangement of bones, sinews, muscles, and feathers. The second factor is spelled out differently in different accounts. Lewis appeals to counterfactuals and causation, but ultimately these boil down to the global fact that the Humean mosaic is arranged in a certain way. In Armstrong's semi-Humean account (Armstrong 1983, see also Dretske 1977; Tooley 1977), it is simply the relevant law or laws, themselves a matter of higher-order relations between universals, that contribute the causal-modal 'oomph' required for a disposition.

Where the fundamental level is concerned, the anti-Humean has a clear-cut way of dealing with these two factors: she gets rid of the first factor, the quality, and reverses the explanatory order with respect to at least some aspect of the second, e.g., the laws. The Humean's qualities, properties about which nothing can be said except that they are what they are and that they underlie certain dispositions, are suspect metaphysical posits (see Bird 2007; Shoemaker 1980, 1998). Once we abandon them in favour of fundamental dispositions, we have what we need to explain other causal and modal notions which the Humean invoked to explain dispositions, in particular the laws. 
When dealing with the non-fundamental, things are a little more complicated. Here the categorical property at issue is in much better standing - the dispositionalist will hardly want to deny that a glass's fragility is in part grounded in or explained by the glass's composition. The first distinctive move of the fundamental dispositionalist is not, thus, readily available. What remains is the second move: laws, modal facts such as counterfactuals, or causal facts are not that which explains the disposition; rather, it is the disposition which explains (at least some of) those other phenomena.

Thus we arrive at what I suggest is the core of the contrast between Humean and antiHumean metaphysics: the order of explanation among the modal-causal phenomena. For the anti-Humean, dispositions are a central explanans rather than a problematic explanandum.

This is the basic idea of what I will suggest under the label 'explanatory dispositionalism'. But it is evidently in need of clarification. For even the committed anti-Humean will not take all dispositions to be unexplained explainers: most dispositions are, like fragility, subject to explanation in terms of underlying structure. Nor should we take the claim to be that some dispositions are unexplained explainers, on pain of running into the problems of fundamental dispositionalism: for if there is no fundamental level, then it may well be that there are no unexplained explainers, dispositional or otherwise.

What we need, then, is a more sophisticated, positive picture of dispositions as explainers. I will develop my own picture in Sect. 6. But before I do so, we should take a look at another recent proposal, due to Azzano (2019), which seems to do exactly what I have suggested: characterize dispositionalism in terms of the explanatory role of dispositions. Section 5 will discuss Azzano's account and find it ultimately unsuccessful too. But there are important lessons to be learned from it, which I will then apply in Sect. 6.

\section{Azzano's explanatory-ontological account}

In a recent paper, Azzano (2019) develops an intriguing suggestion for a better formulation of what he calls 'dispositional realism'. Azzano's focus differs slightly from mine: his dispositional realism is explicitly construed as a realistic view of dispositional properties, thus excluding nominalism from the start; and it is not framed as a matter of anti-Humean metaphysics more generally. The focus is close enough to deserve scrutiny in the present context, all the more since Azzano, too, recommends a move from both fundamentality and (pure) ontology towards a more explanation- or grounding-oriented framing of the debate.

According to Azzano, dispositional realism is about the existence of 'robust powers', where a robust power is a property of an object that is 'the total ground of some W-power.' (Azzano 2019, p. 348), and a W-power in turn is a property whose instantiation (if one can even call it that) consists in nothing more than a dispositional predicate being true of its bearer. W-powers are so weak that even a Rylean could accept them. Azzano does not say what kind of entity (if any) the grounded W-power should be on the dispositional realist view. In order not to saddle the dispositional realist with shadowy entities that double the realm of dispositions, I suggest that we read talk of W-powers as simply standing in for true disposition ascriptions. Thus the character- 
ization of a robust power becomes a claim about truthmaking: a robust power is a property which is the total ground, or the complete truthmaker, of a true disposition ascription. It is important that R-powers are full and not merely partial grounds: as Azzano notes (Azzano 2019, p. 348), the Humean can and often does accept properties that are partial grounds for true disposition ascriptions. In fact, on the standard Humean view that is precisely what a disposition's categorical basis does: it grounds, together with some global fact such as the laws of nature, the truth of a disposition ascription. Robust realism on Azzano's view is distinguished by the claim that some properties, the R-powers, have within themselves all it takes to ground dispositional truths.

Being framed explicitly as a formulation of dispositional realism, Azzano's view is a kind of ontological dispositionalism. As a general characterization of anti-Humeanism, it would violate Generality by assuming property realism. However, it seems to evade my other arguments against ontological dispositionalism, by not relying on a distinction between genuine and merely abundant properties. Instead, it characterizes the properties whose existence is being claimed purely in terms of their explanatory role: they are that which fully grounds or explains certain facts (viz., the possession of W-powers, or equivalently the truth of disposition ascriptions). As Azzano notes, the (ontological) claim that there are robust powers is thus equivalent to the (explanatory) claim that the truth of at least some disposition ascriptions are 'wholly grounded in individual property instances, rather than properties and something else' (Azzano 2019 , p. 348). Hence I take the view to follow my recommended focus on explanation (which Azzano cashes out in terms of grounding).

In fact, Azzano says nothing about the properties that are R-powers except that they are total grounds of the truth of disposition ascriptions. However, while this has the virtue of escaping my argument from Sect. 3, it has the decided drawback of allowing the Humean, once again, to agree with the proposal as it is stated. Here is why.

The Humean may very well accept that there is a property $\mathrm{P}$ that is the total ground for the truth of 'this chunk of salt is disposed to dissolve in water'. She will, of course, go on to offer an account of what kind of property $\mathrm{P}$ is: it is the property of being composed of certain negatively and certain positively charged ions and such that charged ions are subject to Coulomb's law. ${ }^{10}$ A chunk of salt's having $\mathrm{P}$, then, is in turn fully grounded in two facts: the salt's being composed of such ions, and its being in a world where Coulomb's law holds. Since Azzano made no requirement on the grounds of a robust power, the Humean's property P should count as a robust power: it is a property (not a sparse or fundamental one, but that was not required) which is the total ground for the truth of a disposition ascription. To be sure, the Humean claim runs counter to the spirit of Azzano's proposal. But it is consistent with the proposal's letter-which should give us some pause about the letter of the proposal.

How might Azzano respond?

The obvious response is to complain that the Humean's property is conjunctive. To which the Humean will respond, what's wrong with conjunctive properties? What's wrong, the counter-response will probably go, is that conjunctive properties (and the

\footnotetext{
10 Coulomb's law ensures that the positively charged ions in salt bond with the partially negative oxygen atoms in the water, and the negatively charged ions with the partially positive hydrogen atoms.
} 
property of being such that the laws are such-and-such, for that matter) are not genuine properties. The kind of properties we had in mind when formulating dispositionalism were genuine, not abundant. That's all very well, but it takes us right back into liberal ontological dispositionalism and its problem with identifying the division between genuine and merely abundant properties.

Another response might be that the properties at issue are intrinsic properties, while the Humean's property was extrinsic, dependent on how things stand globally and not merely with the property's bearer. But the Humean will respond that her property is just as intrinsic as the dispositionalist's, given the correct definition of intrinsicality (Langton and Lewis 1998); and in any case, it is a well-known fact that dispositions are sometimes extrinsic (McKitrick 2003).

Thus the objection stands: Azzano's account, too, will fail to satisfy either Disagreement or Generality. It will be useful to diagnose what went wrong.

Recall that Azzano characterized R-powers solely in terms of their explanatory role: they are total grounds of W-powers. The lack of a more positive characterization left room for the Humean to come in and claim R-powers within her own framework: she, too, can provide properties that are total grounds of W-powers! In order to preclude such hijacking of the view, Azzano would have to say more about R-powers. But a positive characterization of them, as we have just seen, leads us right back into the problems of ontological dispositionalism. There are two lessons to be drawn here.

The first lesson reiterates what we have seen in Sect. 3: ontological claims about the existence of a certain kind of property, unless they are restricted to the fundamental level, are not going to secure a disagreement with the Humean. If we leave the nature of the relevant properties as unspecified as Azzano does, then the Humean can always come in and give her own account of them; and if we try to prevent that by claiming them to be 'genuine', we commit ourselves to drawing a line which, I have argued, resists drawing in any useful way. My own account in Sect. 6 will, accordingly, appeal to explanation without making any of the dispositionalists' standard existence claims.

The second lesson is that we need a more expansive view of dispositions as explainers and as explananda. Fundamental dispositionalism, when read as a claim about explanation, focussed on just one level where dispositions can act as unexplained explainers. Azzano's account looked beyond the fundamental level, but took into consideration only one specific explanatory job for dispositions: explaining the truth of disposition ascriptions. But he left it entirely open what explains those properties which do the job, the R-powers - and that is precisely where the hypothetical Humean could hijack the view and substitute her own explanatory story. What we need, then, is a claim about the explanation of R-powers - dispositional properties, as opposed to true disposition ascriptions. But we cannot simply reapply Azzano's strategy at the level of R-powers, by claiming that they in turn are fully grounded in further R-powers. Here's an example: the solubility of salt is explained by the Humean in terms of an underlying categorical property (the composition of salt) and some such factor as a law (Coulomb's law). The anti-Humean will want to explain the solubility of salt (an R-power) in terms of the dispositions of its component ions (further R-powers), but her explanation too must include the fact that salt is composed of those ions-a fact which many, including many anti-Humeans, would take to be categorical. So R-powers cannot be generally claimed to be fully grounded in further R-powers; the best we can 
get is partial grounding. We should, then, find a way to understand dispositionalism in terms of the partial grounds of R-powers, or (as I shall now return to calling them) dispositions. The Humean can agree that some dispositions are partially grounded in or explained by further dispositions. The core of my suggestion in Sect. 6 will be that disagreement with the Humean is secured by claiming that all dispositions are explained by further dispositions.

Before I do so, there is one more issue with Azzano's account that we need to look at. His account focusses entirely on the explanatory relations between different kinds of dispositions (W-powers and R-powers), to the exclusion of explanatory relations between dispositions and other phenomena such as laws, causation, and modality. For all Azzano says, the Humean might be right about everything except dispositions. One could coherently (though not, perhaps, very plausibly) adopt a view where the Humean mosaic grounds laws, counterfactuals, and causation, and then add R-powers in on top of that picture but without any explanatory role beyond that of grounding the W-powers. What the anti-Humean wants, however, is something more: on the explanatory characterization that I motivated in Sect. 4, she holds not only that dispositions are real, but also that they are central to the explanatory order of the world.-I should note that this is a criticism not of Azzano's paper, which does not aim to give a general characterization of anti-Humeanism, but rather to give a general characterization of dispositional realism. My criticism is directed only against the temptation to take Azzano's account - and any improved version of it, such as I will offer in the next section - to be the whole story. Let us call the explanatory relations between dispositions and further dispositions, such as the ones that Azzano appealed to, internal dispositional explanations; and the explanatory relations between dispositions and other phenomena, such as laws or causation, external dispositional explanations. Then our third lesson from the discussion of Azzano's proposal is that a fully general characterization of anti-Humeanism must take into account not only internal but also external dispositional explanations.

\section{Explanatory dispositionalism}

This section outlines my suggestion for a better characterization of anti-Humeanism, which satifies both Generality and Disagreement while taking to heart the lessons from Sect. 5. The basic idea of my characterization, which will be modified in what follows, is that

(Int*) All dispositions are explained, if at all, by dispositions; and

(Ext*) For some modal-causal phenomena X (excluding dispositions), every instance of $\mathrm{X}$ is explained by dispositions.

I begin with internal dispositional explanations, as tentatively characterized in (Int*). I will proceed by, first, discussing issues connected with the notion of explanation; and second, issues connected with the notion of a disposition. This will enable us to give a more subtle statement of the view as regards internal dispositional 
explanations. After that, I will turn to the anti-Humean's claims regarding external dispositional explanations, as tentatively characterized in (Ext*).

\section{1 'Explained by'}

Dispositions, I have suggested, are always explained (if at all) in terms of further dispositions. I use the term 'explain' here to stand in for any objective explanatory relation, be it grounding, asymmetric supervenience or what have you; I do not think that the anti-Humean needs to commit to any particular account of objective explanation. ${ }^{11}$ Still, my statement requires elaboration and refinement.

To begin with, the explanatory relations at issue need not be understood to be total explanations (full grounds), for reasons that have already emerged in Sect. 4. The anti-Humean should not insist that the solubility of salt, for instance, is fully explained in terms of further dispositions (e.g., of salt's component ions), but make room for (possibly categorical) facts about composition. What the anti-Humean should insist on, rather, is that dispositions such as those of salt's ions are part of a total explanation of other dispositions, such as salt's water-solubility, not that they are the total explanation. Full explanation should not be required, though it should not be excluded either: for a radical pandispositionalist there are no categorical facts whatsoever, and even the composition of salt will qualify as itself a dispositional fact. The radical pandispositionalist can then require that every disposition is fully explained in terms of further dispositions. But as a general characterization of dispositionalist anti-Humeanism, that will not do.

A first refinement would then be to say that every total explanation of a disposition involves further dispositions. But this is still too strong. For, as we have already seen above, there are those anti-Humeans who would happily explain some dispositions in terms of categorical properties and laws, as long as the laws themselves are ultimately explained in terms of other dispositions. This is a version of fundamental dispositionalism which has been defended by Bird (2016).

We must tread carefully here. The fundamental dispositionalist may want to rephrase my suggestion by saying that every ultimate explanation of a disposition will involve dispositions, where an ultimate explanation is one that goes all the way to the fundamental. But we do not want to commit to there being a fundamental level, and hence we do not want to commit to there being ultimate explanations, on pain of violating Generality. Instead, I suggest we introduce the notion of an extension of an explanation. Think of explanations as chained: $x$ is explained by $y$, and $y$ is explained by $z$, and so on. Explanations might go on to infinity, or they might come to a halt at a fundamental level (or before, if we have emergent phenomena). An explanation (say, ' $x$ is explained by $y$ ') is extended by adding further links of the chain on the explanans side ('... and $y$ is explained by $z$, and $z$ is explained by ...'); for the sake of simplicity we can treat each explanation as a (trivial) extension of itself. Now we can say the following: every explanation of a disposition has an extension that involves further

\footnotetext{
${ }^{11}$ She does, on my suggestion, have to commit to the idea that there are objective explanatory relations in the world. But that seems fair; if there are no objective explanatory relations, then the entire debate does seem misguided.
} 
dispositions. This is the minimal claim that however we explain this or that disposition, we will never reach a level of explanation where we are done with dispositions; we will always at least encounter them somewhere further down the explanatory line.

The minimal statement of dispositional anti-Humeanism could then be phrased as follows:

(Internal) For every disposition that is explained at all, every full explanation of that disposition has an extension which involves dispositions.

To avoid trivial truth, we should probably add:

$\ldots$ and there are dispositions.

(But note that we can think of dispositions as abundant properties for the purposes of (Internal), so the added clause will be very easy to satisfy, and I will drop it in what follows.)

This statement is very minimal indeed. It allows for there to be a fundamental level - in which case it entails fundamental dispositionalism-and for there not to be one. It allows for a picture which has dispositions at the fundamental level, but not at any non-fundamental level (which would make the statement vacuously true). It allows for unexplained dispositions at non-fundamental levels (emergent dispositions) as well as unexplained fundamental and explained non-fundamental dispositions. It also allows for a picture on which we have 'alternating chains' of dispositional and nondispositional explanations - thus we might have some more superficial dispositions such as fragility, which are explained in terms of categorical properties and laws, which in turn are explained in terms of categorical properties and laws, and so on until we reach the fundamental level, where dispositions do explanatory work; or we might have an infinitely descending chain of explanations, where every other link, or perhaps only every 1000th link, involves dispositions; and so on. While these may be less than attractive to many a committed dispositionalist, I would suggest that we still count them as anti-Humean in general, and dispositionalist in particular. We may want to mark a difference between these weaker versions and a stronger version which requires every explanation of a disposition to be itself dispositional; just as we may want to mark a difference of strength on a different axis, between those views that require dispositions to be at least partially, and those that require them to be fully, explained in terms of dispositions. Thus we have seen two ways in which the minimal statement (Internal) can be strengthened, and made less minimal:

Strengthening 1: Replace 'involves dispositions' with 'involves only dispositions'. Strengthening 2: Delete 'has an extension which'.

\section{2 'Disposition'}

How we understand (Internal) depends on how we understand the explanatory relations at issue; but it also depends on how we understand dispositions. Here, too, I will suggest a minimal characterization that can be added to in different ways. 
At first pass, a disposition is a property that has a special connection to its causalmodal profile: it has that profile essentially, or it is the property it is in virtue of having that causal-modal profile.

This is a rather vague formulation, which allows for different precisifications, each of which will in turn give rise to a slightly different version of dispositionalism.

First, what do we mean by a 'causal-modal profile'? Traditionally, this would be a particular counterfactual whose truth is entailed by the property (and is so entailed in virtue of the property's essence or identity). Of course, such counterfactuals would have to be qualified to allow for finks and masks (though Bird 2007 argues that this is not the case at the fundamental level). Bird (2007) holds (and Bird 2016 still implicitly assumes) that a genuine dispositional property corresponds to a single counterfactual conditional. Others will link a dispositional property to a whole range of such counterfactuals, even an infinite range as described in a property's Ramsey sentence (Jacobs 2011). Yet others argue that a dispositional property is linked not to one or many counterfactuals, but to a different kind of modal profile, a graded possibility (Vetter 2015) or even a sui generis modal force, a dispositional tendency (Anjum and Mumford 2018). Let us stick to 'causal-modal profile' to cover all of these views.

Second, how are we to understand the relation between the dispositional property and its causal-modal profile? On a view which some call the 'pure powers view', a disposition is a property that just is a particular modal-causal profile: that profile completely specifies and exhausts its essence or nature (again, Bird 2007 will serve as an example, as do Anjum and Mumford (2018) and Mumford and Anjum (2011)). On a different family of views, sometimes called 'powerful qualities views', there is more to a disposition than its causal-modal profile. On these views, the properties in question have both qualitative and dispositional aspects. Those two aspects are then either claimed to be two intimately related aspects of the property, two sides of the same metaphorical coin (Martin 1997) and necessarily linked (Williams 2019), or even identical with each other (Heil 2003); or else, it is argued that the property, understood as a quality, still directly gives rise to-grounds, or serves as a truthmaker to-its own causal-modal profile (Jacobs 2011; Tugby 2012; actually, things are a little more complicated with this view, as detailed in the following footnote ${ }^{12}$ ).

\footnotetext{
12 The grounding or truthmaking view, strictly speaking, lends itself to my characterization of dispositionalism only on some specifications. For if we think that a property grounds its causal/modal profile (or makes true certain causal-modal facts), we can still ask why it does so. If it is in virtue of the property's own nature (and nothing else), then we have a disposition in the sense suitable for my characterization. However, if the grounding relation is brute, or holds in virtue of the nature of a distinct, causal-modal property, then we do not. In more recent work, Matthew Tugby has advocated a view of the latter kind (Tugby 2020), which he does not label 'dispositionalist', for reasons closely related to the ones I give here (personal communication). Another closely related, but not necessarily dispositionalist view, is what (Smith 2016) has suggested under the label 'non-recombinatorial quidditism': the view that while properties themselves are quiddities, there is nonetheless a metaphysically necessary connection between a property and its causal-modal (Smith says: its nomological) profile. Smith herself says that her view is not a dispositional one because her quiddities determine, rather than being determined by, the facts of the causal-modal profile, but that sets her view apart only from both Bird's pure power view and the double-aspect view, not from the truthmaker view. I suggest that we take non-recombinatorial quidditism to be on the fence, as detailed above: if the metaphysically necessary connection between a property and its causal-modal profile is taken to hold solely in virtue of the property's nature, then we can call its quiddities 'dispositions'; if the metaphysical necessities in question are said to be brute or to have their source in anything other than the
} 
Note, however, that merely claiming the existence of dispositions on any of the readings I have given will not be sufficient for the statement of an anti-Humean view. For the Humean can accept the existence of properties of any of these kinds-pure powers, double-aspect powers, or properties that make true causal-modal statementsas long as she is entitled to give her own explanation of these properties, in terms of categorical properties and laws of nature, possible worlds, or whatever her preferred explanatory strategy might be. What precludes a Humean understanding of dispositions is not our characterization of the dispositions themselves, but of how they are explained, i.e., (Internal).

A third point needs to be clarified on the use of 'disposition'. I said that a disposition is a property with a special connection to its causal-modal profile. Thus, as it stands, (Internal) quantifies over dispositions, thereby committing, for its non-vacuous truth, to their existence. In Sect. 3, I objected that this goes against Generality: we can be antiHumeans, even dispositionalists, without being realists about properties. Although it is not a common stance, I think that we should make room for nominalist antiHumeanism. But we should note that (Internal) should really be understood to quantify over instances of dispositions: it is not the universal (or trope, or ...) property of watersolubility that is explained in terms of the dispositions of salt's constituent ions; it is the water-solubility of this chunk of salt that is so explained, or better yet: this chunk of salt is water-soluble because its constituent ions are disposed to bond with the ions in water just so. This is a formulation (choosing 'because' to elude the need for nominalization) which even a nominalist can subscribe to. We could rephrase (Internal) accordingly:

(Internal-) Whenever something $x$ is disposed to $\Phi$, and its being disposed to $\Phi$ has an explanation, then every explanation of $x$ 's being disposed to $\Phi$ has an extension which involves something $y$ being disposed to $\Psi$.

(Further modifications are required if the nominalist is opposed to quantifying over explanations too, but I leave those to the imagination of the reader.) For ease of exposition, I will continue to use quantification over dispositions and (Internal), but I ask the reader to understand those as abbreviations of the nominalistically acceptable formulations. Besides being acceptable to the anti-Humean nominalist, (Internal-) has the advantage of saying what dispositionalism is without appealing to the essence or nature of a property - a notion which some Humeans profess not even to understandand thus facilitating the debate with one's competitor.

Independently of the choice between (Internal) and (Internal-), it is important to note that the explanatory relation in question is to hold between instances, and is the kind of explanation that we are after when giving scientific explanations of phenomena; it is not one that holds between properties themselves, e.g. as constituting each other's identity. Anti-Humeans, as we have seen above, can take different views on how the identity of a disposition is constituted, ${ }^{13}$ none of which should be incompatible with (Internal).

Footnote 12 continued

nature of the properties in question, then the view that Smith suggests, like the view developed in Tugby (2020), will still count as broadly anti-Humean in the sense of Sect. 1, but not as dispositionalist.

13 Yates (2018) even argues that fundamental dispositions may constitutively depend on non-fundamental qualities. 
So I propose that we understand (Internal) (i) to quantify over instances of disposition, and (ii) to be supplemented with the following minimal understanding of what a disposition is:

(Disposition) A disposition is a property that has its causal-modal profile in virtue of being the property that it is.

(Alternatively: to be disposed is to be some way F such that one has a causalmodal profile just in virtue of being F. $)^{14}$

\subsection{External dispositional explanations}

We have seen in Sect. 5 that a characterization of anti-Humeanism should also have an external component: dispositions explain not just dispositions, but other phenomena in the vicinity as well. But different anti-Humeans offer explanations of different phenomena. They may give an account of laws in terms of dispositions (Bird 2007) or else argue that, given dispositions, laws are superfluous (Mumford 2004). They may use dispositions to ground laws, and thus a kind of necessity (again, Bird 2007), or possibilities (Vetter 2015), or something in between (Anjum and Mumford 2018), and remain neutral on any of the other items in the list. What unites them is that they consider dispositions to be an explanans rather than an explanandum vis-à-vis at least some of the other causal-modal phenomena. (I limit the statement to causal-modal phenomena, because Humeans, too, have been known to give dispositional accounts of other phenomena, e.g. value-see Smith et al. 1989.) ${ }^{15}$

I gave a tentative statement of the external side to anti-Humeanism in (Ext*), but we can now see that the considerations that apply are very similar to the ones we considered for internal dispositional explanations. Mimicking the formulation we gave above, we can formulate the external explanatory side of dispositional anti-Humeanism as follows: for some modal/causal phenomena $\mathrm{X}$, every instance of $\mathrm{X}$ is explained dispositionally at least at some stage; or canonically:

(External) For some modal/causal phenomena X (excluding dispositions), every instance of $\mathrm{X}$ is such that every explanation of it has an extension which involves dispositions.

Again, we allow for partial grounding, for even a dispositionalist view of, say, causation need not claim that causal facts are fully explained in terms of dispositions (rather than involving facts about spatiotemporal location, which may be considered categorical). Some views — such as dispositionalist views of laws or modality - may well appeal to full grounding, however. Again, we appeal to extensions of explanations in order for (External) to allow for a number of scenarios. It allows, for instance, that not every law is directly explained in terms of dispositions; some higher-order laws might

\footnotetext{
14 One way of reading the alternative formulation is as a statement of generic essence, thus drawing on the resources offered by Vogt (ms).

15 Talk of 'causal-modal phenomena' is deliberately vague, since different dispositionalists may want to focus on different phenomena. We might alternatively describe the phenomena as 'oomphy'. The dispositionalist is not committed to thinking that they form as neat and unified a package as the Humean thinks they do.
} 
be explained in terms of other laws, and so on all the way down to the fundamental laws, which are in turn explained by dispositions. (Again, the anti-Humean who suggests such a view is Bird 2016.) It allows even for laws, modality, causation, or whatever other phenomena we want to include to play a role in explaining some dispositions, a possibility which we have seen should be left open, and hence it allows for alternating chains of explanations-laws in terms of dispositions, dispositions in terms of laws, and laws again in terms of dispositions. Again, I believe that such views should be counted as (minimally) anti-Humean. Like its internal counterpart, (External) can be strengthened in two ways: either replacing 'involves dispositions' by 'involves only dispositions', requiring dispositions to be the total ground of the relevant facts; or deleting 'has an extension which', thus requiring every instance of the relevant phenomena to be directly explained by dispositions. (External) can and should be supplemented with the same minimal characterization of what a disposition is. And like its internal counterpart, (External) can also be rephrased so as to be acceptable for the nominalist (though not all the resulting accounts will be equally attractive when combined with a nominalist reading).

There are two disanalogies between (Internal) and (External). One is that (External) is not conditionalized on 'if it [the instance of $\mathrm{X}$ ] is explained at all ...'. (Internal) was so conditionalized to make room for the possibility of unexplained, fundamental or emergent, dispositions. For obvious reasons, (External) should not make room for similarly unexplained non-dispositional facts. The second disanalogy is that while we can read 'disposition' in (Internal) always as 'instance of a disposition', this is not so for (External). If our X is causation or possibility, then it is plausible that dispositional explanations of its instances will appeal to instances of dispositions; if, however, our $\mathrm{X}$ is lawhood, then dispositional explanations may be better off appealing to the nature of the disposition itself. Hence I am leaving 'disposition' in (External) deliberately ambiguous between the property itself and its instances.

I call the conjunction of the two parallel statements (Internal) and (External) Explanatory Dispositionalism. My proposal is that explanatory dispositionalism is the best general characterization that we can give of (dispositional) anti-Humeanism.

\subsection{Meeting the requirements}

I hope that it has become clear from my discussion how Explanatory Dispositionalism was built so as to satisfy our requirements. But I want to end by taking them up again explicitly.

Let me take Disagreement first. Explanatory dispositionalism, in a nutshell, is the view that however far we go down in the explanatory order of the world, we will never get rid of dispositions. The Humean (if we conceive her view indepedently of the question of a fundamental level) will be committed to the view that as you go down the explanatory order of the world, you will always at some point get rid of dispositions and other 'oomphy' phenomena. If there is a fundamental level that explains everything else, Explanatory Dispositionalism entails (as it should) that this level is dispositional; Humeanism entails that it is not. If there is no fundamental level, Explanatory Dispositionalism entails that as explanations go on to infinity, there will always be a 
dispositional explanation further down the explanatory line; Humeanism entails that dispositional explanations must always give out at some point. On neither assumption are the two views compatible. (Note that there is a lesson for anti-Humeanism broadly conceived: if we think of Humeanism as the view that modal/causal phenomena are always explained in terms of non-modal/causal phenomena, then anti-Humeanism broadly conceived is just the negation of that claim, and different forms of antiHumeanism will focus on different modal/causal phenomena-dispositions, laws, subjunctives, etc.)

How about Generality? It is difficult to provide proof of such a claim, for strictly this would require a survey of every available statement that might be considered to be dispositionalist. But I hope my discussion of Explanatory Dispositionalism has already gone some way towards showing how it can accommodate a number of different versions of dispositionalist anti-Humeanism. It is worth pointing out in addition how Explanatory Dispositionalism avoids the pitfalls that beset other attempts at a general statement of dispositional anti-Humeanism. One complaint that I have raised against fundamental dispositionalism was its commitment to there being a fundamental level in nature. It is obvious that Explanatory Dispositionalism carries no such commitment, either to there being, or to there not being, a fundamental level. In fact, Explanatory Dispositionalism does not even have a commitment on the explanatory order of the world-beyond the commitment that it explicitly states about the explanatory role of dispositions. Thus Explanatory Dispositionalism should be acceptable even to an anti-Humean who, like Heil (2003), rejects the notion of 'levels of reality', as long as they agree that some things' being some way (e.g., salt being disposed to dissolve in water) is explained in some way by some (potentially distinct) things' being some way (e.g., salt's ions being arranged and charged in certain ways). In principle, it is compatible even with priority monism, the view that the fundamental level consists not of the smallest components of everything but rather of 'the Whole' itself, and thus explanation at least at this stage must go from the smaller explananda to a much larger explanandum (as argued in Schaffer 2010, and considered in Heil 2003). A dispositionalist who is also a monist would have to ground all dispositions in the dispositions of the universe itself.

Most dispositionalists, however, are not monists but subscribe to the explanation of larger objects in terms of their component parts. And when coupled with that view, explanatory dispositionalism can make good sense of the initial dispositionalist idea that things are 'active', in the minimal sense of having within themselves the sources of their causal, nomic, and modal properties. For given such a view, we can see that the powers of ordinary objects and ourselves are explained in terms of the dispositions of their parts. Thus a bird's ability to fly, for instance, is explained in terms of the dispositions of its muscles, bones, sinews, feathers, and so on; and those dispositions are in turn explained by the dispositions of the molecules that make up those parts of its body, and so on. Thus whatever enables the bird, or a sugar cube, or you and me to do one thing or another, or what makes them and us subject to a particular law, or contribute causally to some processes, is 'immanent' in the individuals and not 'superimposed' on them, in Ellis's words (Ellis 2001, p. 1). I believe this is the best sense we can make of 'activity' as outlined in Sect. 1. 
Acknowledgements For very helpful comments and discussions, I would like to thank Simona Aimar, Max Goetsch, Can Laurens Löwe, Dominik Perler, Wolfgang Schwarz, and Lisa Vogt, as well as two anonymous reviewers, whose comments did much to improve the paper. Significant parts of this paper were written in the context of the Centre for Advanced Studies in the Humanities "Human Abilities", which provided a stimulating and congenial environment even in these difficult times. I gratefully acknowledge funding for the Centre from the Deutsche Forschungsgemeinschaft (DFG, German Research Foundation-Grant number 409272951).

Funding Open Access funding enabled and organized by Projekt DEAL.

Open Access This article is licensed under a Creative Commons Attribution 4.0 International License, which permits use, sharing, adaptation, distribution and reproduction in any medium or format, as long as you give appropriate credit to the original author(s) and the source, provide a link to the Creative Commons licence, and indicate if changes were made. The images or other third party material in this article are included in the article's Creative Commons licence, unless indicated otherwise in a credit line to the material. If material is not included in the article's Creative Commons licence and your intended use is not permitted by statutory regulation or exceeds the permitted use, you will need to obtain permission directly from the copyright holder. To view a copy of this licence, visit http://creativecommons.org/licenses/by/4.0/.

\section{References}

Anjum, R. L., \& Mumford, S. (2018). What tends to be: The philosophy of dispositional modality. London: Routledge.

Armstrong, D. (1983). What is a law of nature?. Cambridge: Cambridge University Press.

Armstrong, D. (2004). Truth and truthmakers. Cambridge: Cambridge University Press.

Azzano, L. (2019). The question of realism for powers. Synthese, 196, 329-354.

Bhogal, H. (2017). Minimal anti-Humeanism. Australasian Journal of Philosophy, 95, 447-460.

Bird, A. (2007). Nature's metaphysics: Laws and properties. Oxford: Oxford University Press.

Bird, A. (2016). Overpowering: how the powers ontology has overreached itself. Mind, 125, 341-383.

Bird, A. (2018). Fundamental powers, evolved powers, and mental powers. Aristotelian Society Supplementary, 92, 247-275.

Blackburn, S. (1990). Filling in space. Analysis, 50, 62-65.

Bliss, R. (2019). What work the fundamental? Erkenntnis, 84, 359-379.

Dorr, C., \& Hawthorne, J. (2013). Naturalness. Oxford Studies in Metaphysics, 8, 3-77.

Dretske, F. (1977). Laws of nature. Philosophy of Science, 44, 248-268.

Ellis, B. (2001). Scientific essentialism. Cambridge: Cambridge University Press.

Frankfurt, H. (1998). The importance of what we care about. New York: Cambridge University Press.

Groff, R. (2013). Whose powers? Which agency? In R. Groff \& J. Greco (Eds.), Powers and capacities in philosophy: The new Aristotelianism (pp. 207-227). London: Routledge.

Harré, R. (1970). Powers. British Journal for the Philosophy of Science, 21, 81-101.

Heil, J. (2003). From an ontological point of view. Oxford: Oxford University Press.

Jacobs, J. D. (2011). Powerful qualities, not pure powers. The Monist, 94, 81-102.

Janssen-Lauret, F. (2017). The Quinean roots of Lewis's humeanism. The Monist, 100, 249-265.

Lange, M. (2009). Laws and lawmakers. Science, metaphysics, and the laws of nature. Oxford: Oxford University Press.

Langton, R., \& Lewis, D. (1998). Defining 'intrinsic'. Philosophy and Phenomenological Research, 58, $333-345$.

Lewis, D. (1970). Causation. The Journal of Philosophy, 70, 556-567.

Lewis, D. (1983). New work for a theory of universals. Australasian Journal of Philosophy, 61, 343-377.

Lewis, D. (1986). On the plurality of worlds. Oxford: Blackwell.

Lewis, D. (1986). Philosophical papers (Vol. II). Oxford: Oxford University Press.

Lewis, D. (1994). Reduction of mind. In S. Guttenplan (Ed.), Companion to the philosophy of mind (pp. 412-431). Oxford: Blackwell.

Loewer, B. (1996). Humean supervenience. Philosophical Topics, 24, 101-127. 
Martin, C. B. (1997). On the need for properties: the road to Pythagoreanism and back. Synthese, 112, 193-231.

Martin, C. B., \& Heil, J. (1998). Rules and powers. Philosophical Perspectives, 12, 284-312.

Maudlin, T. (2007). The metaphysics within physics. Oxford: Oxford University Press.

McKenzie, K. (2011). Arguing against fundamentality. Studies in History and Philosophy of Science Part A, 42, 244-255.

McKitrick, J. (2003). A case for extrinsic dispositions. Australasian Journal of Philosophy, 81, 155-174.

Mellor, D. H. (1974). In defense of dispositions. The Philosophical Review, 83, 157-181.

Molnar, G. (2003). Powers. A study in metaphysics. Oxford: Oxford University Press.

Mumford, S. (2004). Laws in nature. London: Routledge.

Mumford, S., \& Anjum, R. L. (2011). Getting causes from powers. Oxford: Oxford University Press.

Quine, W. V. O. (1948). On what there is. Review of Metaphysics, 2, 21-38.

Schaffer, J. (2003). Is there a fundamental level? Noûs, 37, 498-517.

Schaffer, J. (2004). Two conceptions of sparse properties. Pacific Philosophical Quarterly, 85, 92-102.

Schaffer, J. (2009). On what grounds what. In D. J. Chalmers, D. Manley, \& R. Wasserman (Eds.), Metametaphysics. New essays on the foundation of ontology (pp. 347-383). Oxford: Oxford University Press.

Schaffer, J. (2010). Monism: the priority of the whole. Philosophical Review, 119, 31-76.

Schaffer, J. (2015). What not to multiply without necessity. Australasian Journal of Philosophy, 93, 644664.

Shoemaker, S. (1980). Causality and properties. In P. van Inwagen (Ed.), Time and cause (pp. 109-135). Dordrecht: Reidel.

Shoemaker, S. (1998). Causal and metaphysical necessity. Pacific Philosophical Quarterly, 79, 59-77.

Smith, M., Lewis, D., \& Johnston, M. (1989). Dispositional theories of value. Aristotelian Society Supplementary, 63, 89-174.

Smith, D. (2016). Quid quidditism est? Erkenntnis, 81, 237-257.

Thomson, J. J. (1983). Parthood and identity across time. Journal of Philosophy, 80, 201-220.

Tooley, M. (1977). The nature of laws. Canadian Journal of Philosophy, 7, 667-698.

Tugby, M. (2012). Rescuing dispositionalism from the ultimate argument: reply to barker and smart. Analysis, 72, 723-731.

Tugby, M. (2013). Platonic dispositionalism. Mind, 122, 451-480.

Tugby, M. (2020). Grounding theories of powers. Synthese. https://doi.org/10.1007/s11229-020-02781-2.

Vetter, B., \& Work, R. (2011). Modality without possible worlds. Analysis, 71, 742-754.

Vetter, B. (2015). Potentiality: From dispositions to modality. Oxford: Oxford University Press.

Vetter, B. (2018). Evolved powers, artefact powers, and dispositional explanations. Aristotelian Society Supplementary, 92, 277-297.

Vogt, L. Austere dispositional nominalism, unpublished manuscript.

Whittle, A. (2009). Causal nominalism. In T. Handfield (Ed.), Dispositions and causes (Vol. 9, pp. 242-285). Oxford: Oxford University Press.

Williams, N. (2019). The powers metaphysic. Oxford: Oxford University Press.

Yates, D. (2018). Inverse functionalism and the individuation of powers. Synthese, 195, 4525-4550.

Publisher's Note Springer Nature remains neutral with regard to jurisdictional claims in published maps and institutional affiliations. 